\title{
Neoadjuvant Chemotherapy in Pancreatic Cancer: An Appraisal of the Current High-Level Evidence
}

\author{
Philip C. Müller ${ }^{a, b}$ Michael C. Frey ${ }^{b, c}$ Claudio M. Ruzza ${ }^{a, b} \quad$ Felix Nickel $^{d}$ \\ Christian Jost $^{\text {b, e }}$ Christoph Gwerder ${ }^{\text {b,f }}$ Thilo Hackert $^{d}$ Kaspar Z'graggen ${ }^{a, b}$ \\ UIf Kessler ${ }^{a, b, c}$
}

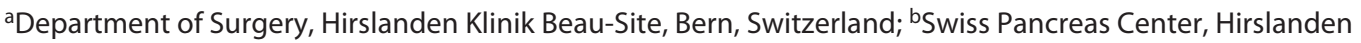
Klinik Beau-Site, Bern, Switzerland; 'Department of Pediatric Surgery, University Hospital Bern, University of Bern, Bern, Switzerland; 'Department of General, Visceral and Transplantation Surgery, University Hospital

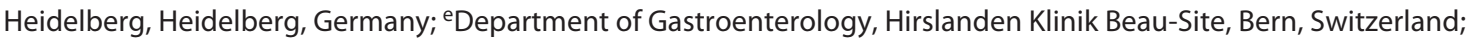
fDepartment of Oncology, Hirslanden Klinik Beau-Site, Bern, Switzerland

\section{Keywords}

Pancreatic cancer · Neoadjuvant chemotherapy · Precision medicine $\cdot$ Neoadjuvant therapy $\cdot$ FOLFIRINOX

\begin{abstract}
At the time of diagnosis, only about $20 \%$ of patients with pancreatic ductal adenocarcinoma (PDAC) have resectable disease. PDAC treatment necessitates a multidisciplinary approach, and adjuvant chemotherapy after upfront resection is an established means of preventing recurrence. Neoadjuvant chemotherapy (NAT), originally introduced to downstage tumor size, is nowadays more frequently used for selection of patients with favorable tumor biology and to control potential micrometastases. While NAT is routinely applied in locally advanced (LA) PDAC, there is increasing evidence demonstrating benefits of NAT in borderline resectable (BR) PDAC. The concept of NAT has recently been tested in resectable PDAC, but to date NAT has been restricted to clinical trials, as the data are limited and no clear ben-
\end{abstract}

efits have yet been shown in this patient group. This review summarizes the current evidence for NAT in resectable, BR, and LA PDAC, with a focus on high-level evidence and randomized controlled trials.

(c) 2020 S. Karger AG, Basel

\section{Background}

In 2020, pancreatic ductal adenocarcinoma (PDAC) was the tenth most common cancer, accounting for $3 \%$ of all new cancer cases, and the fourth leading cause for cancer mortality, responsible for $8 \%$ of all cancer deaths [1]. The importance of PDAC will grow, as the prevalence is expected to rise. Although the treatment of pancreatic cancer has improved over recent years, the prognosis is still dismal, with a 5-year survival rate of only $10 \%$ in Switzerland [2]. The sole potentially curative treatment is surgical resection followed by adjuvant chemotherapy. Due to the aggressiveness of the disease and the late onset 
Table 1. Definitions of resectability according to the AHPBA/SSO/SSAT and NCCN classifications

\begin{tabular}{|c|c|c|c|c|c|c|}
\hline & \multicolumn{3}{|c|}{ AHPBA/SSO/SSAT classification } & \multicolumn{3}{|l|}{ NCCN classification } \\
\hline & resectable & borderline resectable & locally advanced & resectable & borderline resectable & locally advanced \\
\hline \multicolumn{7}{|l|}{ Venous } \\
\hline $\mathrm{PV} / \mathrm{SMV}$ & $\begin{array}{l}\text { No contact } \\
\text { No encasement }\end{array}$ & $\begin{array}{l}\text { Contact or encasement } \\
\text { Short venous segment } \\
\text { occlusion } \\
\text { Reconstructible }\end{array}$ & Not reconstructible & $\begin{array}{l}\text { No contact } \\
\leq 180^{\circ} \text { contact without } \\
\text { vein contour irregularity }\end{array}$ & $\begin{array}{l}\text { Contact }>180^{\circ} \\
\leq 180^{\circ} \text { with contour } \\
\text { irregularity or } \\
\text { thrombosis of the vein } \\
\text { Reconstructible }\end{array}$ & $\begin{array}{l}\text { Not } \\
\text { reconstructible }\end{array}$ \\
\hline \multicolumn{7}{|l|}{ Arterial } \\
\hline SMA & No contact & Contact $\leq 180^{\circ}$ & Contact $>180^{\circ}$ & No contact & Contact $\leq 180^{\circ}$ & Contact $>180^{\circ}$ \\
\hline $\mathrm{CHA}$ & No contact & $\begin{array}{l}\text { Direct contact } \\
\text { Short segment } \\
\text { encasement }\end{array}$ & $\begin{array}{l}\text { Long segment } \\
\text { encasement }\end{array}$ & No contact & $\begin{array}{l}\text { Contact without } \\
\text { extension to CA or HA } \\
\text { bifurcation }\end{array}$ & $\begin{array}{l}\text { Not } \\
\text { reconstructible }\end{array}$ \\
\hline $\mathrm{CA}$ & No contact & No contact & Contact & No contact & $\begin{array}{l}\text { Contact } \leq 180^{\circ} \\
\text { Contact }>180^{\circ} \text { without } \\
\text { contact of aorta/ } \\
\text { uninvolved GDA }\end{array}$ & $\begin{array}{l}>180^{\circ} \\
\leq 180^{\circ} \text { and aortic } \\
\text { involvement }\end{array}$ \\
\hline
\end{tabular}

AHPBA, American Hepato-Pancreato-Biliary Association; CA, celiac axis; CHA, common hepatic artery; GDA, gastroduodenal artery; HA, hepatic artery; NCCN, National Comprehensive Cancer Network; PV, portal vein; SMA, superior mesenteric artery; SMV, superior mesenteric vein; SSAT, Society for Surgery of the Alimentary Tract; SSO, Society of Surgical Oncology; ${ }^{\circ}$, involvement of vascular circumference in degrees.

of symptoms, only about $15-20 \%$ of the patients have a localized tumor at the time of presentation and therefore a chance of cure $[3,4]$. For allocation to the most suitable form of treatment, assessment of resectability at the time of diagnosis is of paramount importance.

In cancers of the esophagus [5-7], rectum [8-11], and stomach [12-14], the introduction of neoadjuvant chemotherapy (NAT) significantly improved outcomes. With regard to PDAC, there is increasing interest in and experience of NAT in the form of chemotherapy or combined radiochemotherapy. The use of NAT in the treatment of PDAC has several potential advantages. NAT may increase the rate of margin-negative $(\mathrm{R} 0)$ resection in borderline resectable (BR) PDAC and downstage selected locally advanced (LA) tumors [15-18].

Almost half of the patients undergoing curative resection for PDAC do not receive adjuvant chemotherapy due to postoperative morbidity or a poor general condition [1921]. With NAT, the proportion of patients receiving chemotherapy could be increased [22], leading to improved locoregional and systemic control of the disease [23].

Patient selection is done according to tumor biology. $\mathrm{Pa}-$ tients with particularly aggressive tumors that progress under NAT would not undergo surgical resection with the associated perioperative morbidity and mortality [24]. The aim of this study is to present a review of the current literature of NAT in the setting of resectable and BR/LA PDAC.

\section{Resectability}

The primary objective of surgery is to achieve a margin-negative (R0) resection. Although R0 resections are defined differently, an $\mathrm{R} 0$ resection with a $1-\mathrm{mm}$ tumorfree margin has been shown to correlate with improved survival compared to a $<1-\mathrm{mm}$ tumor clearance [25-27]. $\mathrm{PDAC}$ is deemed resectable if negative resection margins can be achieved. Assessment of resectability is based on preoperative imaging, usually triphasic contrast-enhanced computed tomography (CT) and/or magnetic resonance imaging (MRI) with 1 - to 2 -mm slices.

Localized tumors are divided into resectable, BR, and LA disease based on the venous and arterial involvement. The classifications most often applied are those of the American Hepato-Pancreato-Biliary Association (AHPBA)/Society of Surgical Oncology (SSO)/Society for Surgery of the Alimentary Tract (SSAT) and the National Comprehensive Cancer Network (NCCN) (Table 1). In patients with resectable PDAC, upfront surgery is recommended. However, it is important to identify BR and LA disease, where patients may benefit from NAT. In such patients, NAT improves the rate of margin-negative resection. In addition to the local anatomical situation, biological factors such as carbohydrate antigen (CA) 19-9 levels are increasingly taken into account when assessing resectability. Preoperative CA 19-9 levels influence both 
the likelihood of an R0 resection and the probability of long-term survival $[28,29]$. According to an international consensus, patients with an anatomically resectable PDAC and CA 19-9 levels over $500 \mathrm{IU} / \mathrm{mL}$ are nevertheless defined as BR [30]. In other high-volume centers, a CA 19-9 level over $200 \mathrm{IU} / \mathrm{mL}$ is considered to indicate that the patients will most likely benefit from NAT [31]. When interpreting CA 19-9 levels, it has to be considered that in cases with obstructive jaundice, CA 19-9 cannot reliably distinguish between benign and malignant diseases [32, 33]. Furthermore, the application of CA 19-9 is limited by the fact that around $10 \%$ of the population are CA 19-9 nonsecretors due to a missing enzyme for the sialyl Lewis antigen epitope production [32]. In addition to tumor anatomy and biological factors, treatment should be guided by the patient's age, comorbidities, and especially performance status [34].

\section{Adjuvant Chemotherapy}

The standard of care for patients with resectable PDAC is upfront resection followed by adjuvant chemotherapy. Several possible chemotherapy regimens have been evaluated in randomized controlled trials (RCTs).

The ESPAC-1 trial, a first pivotal RCT, showed a significant survival benefit of adjuvant chemotherapy in patients with resected pancreatic cancer. Patients after pancreatic resection received either chemotherapy alone (5FU), chemoradiotherapy (CRT) alone (20 Gy with 5-FU), both CRT and chemotherapy, or observation only. The estimated 5 -year survival rate was $21 \%$ in patients who received chemotherapy and $8 \%$ in patients without chemotherapy $(p=0.009)$. Adjuvant chemotherapy with 5 -FU became the standard of care after the ESPAC-1 study [35].

The German CONKO-001 trial compared adjuvant chemotherapy with gemcitabine ( 6 cycles) to surveillance only in 368 patients undergoing curative resection for PDAC. Disease-free survival (DFS), the primary endpoint of the study, was longer in patients receiving gemcitabine (13.4 vs. 6.7 months) [36].

The ESPAC-3 trial compared the 2 previously mentioned chemotherapeutic agents, gemcitabine and 5-FU, in 1,088 patients undergoing pancreatic resection. The study found no difference in median survival (5-FU 23.0 months vs. gemcitabine 23.6 months; $p=0.39$ ) or median progression-free survival (PFS) (5-FU 14.1 months vs. gemcitabine 14.3 months; $p=0.53$ ) [37].

The subsequent ESPAC- 4 trial compared a combination of 5 -FU (capecitabine, $1,660 \mathrm{mg} / \mathrm{m}^{2}$ for 6 cycles) and

Neoadjuvant Chemotherapy in Pancreatic

Cancer gemcitabine $\left(1,000 \mathrm{mg} / \mathrm{m}^{2}\right.$ for 6 cycles $)$ to gemcitabine monotherapy. In 732 randomized patients, the combination of 5-FU and gemcitabine led to a median overall survival (OS) of 28 months, compared to 25.5 months with gemcitabine alone $(p=0.032)$ [38].

After promising results in the palliative setting, the PRODIGE 24/CCTG-PA.6 trial evaluated a new regimen consisting of a combination of oxaliplatin, irinotecan, and 5-FU (FOLFIRINOX), which proved to be more efficient than gemcitabine in the palliative setting. The study compared modified FOLFIRINOX (mFOLFIRINOX), with a reduced irinotecan dose and no 5-FU bolus, to gemcitabine in patients with a good general condition (ECOG 0-1). Patients receiving mFOLFIRINOX showed a significantly longer OS (54.4 vs. 35 months; $p=0.003$ ). The DFS was 21.6 months, compared to 12.8 months $(p<0.001)$ with gemcitabine alone [39]. In contrast to these promising developments, the recent randomized controlled APACT trial failed to demonstrate a beneficial effect of combining nab-paclitaxel with gemcitabine versus gemcitabine monotherapy in the adjuvant setting [40]. Consequently, the use of nab-paclitaxel should be restricted to patients unfit for FOLFIRINOX or gemcitabine/capecitabine.

\section{Neoadjuvant Therapy in LA PDAC}

Thirty to forty percent of patients with PDAC are initially diagnosed with LA PDAC [41]. As shown in Table 1, LA PDAC is still nonmetastatic, but due to the local growth, curative resection is not possible at the time of diagnosis. Multiple studies have shown conversion from unresectable to resectable disease after NAT in the form of FOLFIRINOX- or gemcitabine-based NAT [42-45], but high-level evidence from RCTs on the best possible treatment of NAT in LA PDAC is sparse. According to the NCCN guidelines, the pretreatment workup of LA PDAC necessitates biopsy-proven PDAC and should, furthermore, include CA 19-9 levels to monitor treatment response. Depending on the performance status, NAT should be started. However, the recommended therapy varies among the ESMO (European Society for Medical Oncology) [46], NCCN [47], and ASCO (American Society of Clinical Oncology) [48] guidelines (Fig. 1).

Conversion rates to surgery vary widely, from 4 to $75 \%$, and selection of suitable candidates for surgical resection after NAT should not be based solely on the local disease response on cross-sectional imaging (CT or MRI), as radiological restaging after NAT can be mis- 


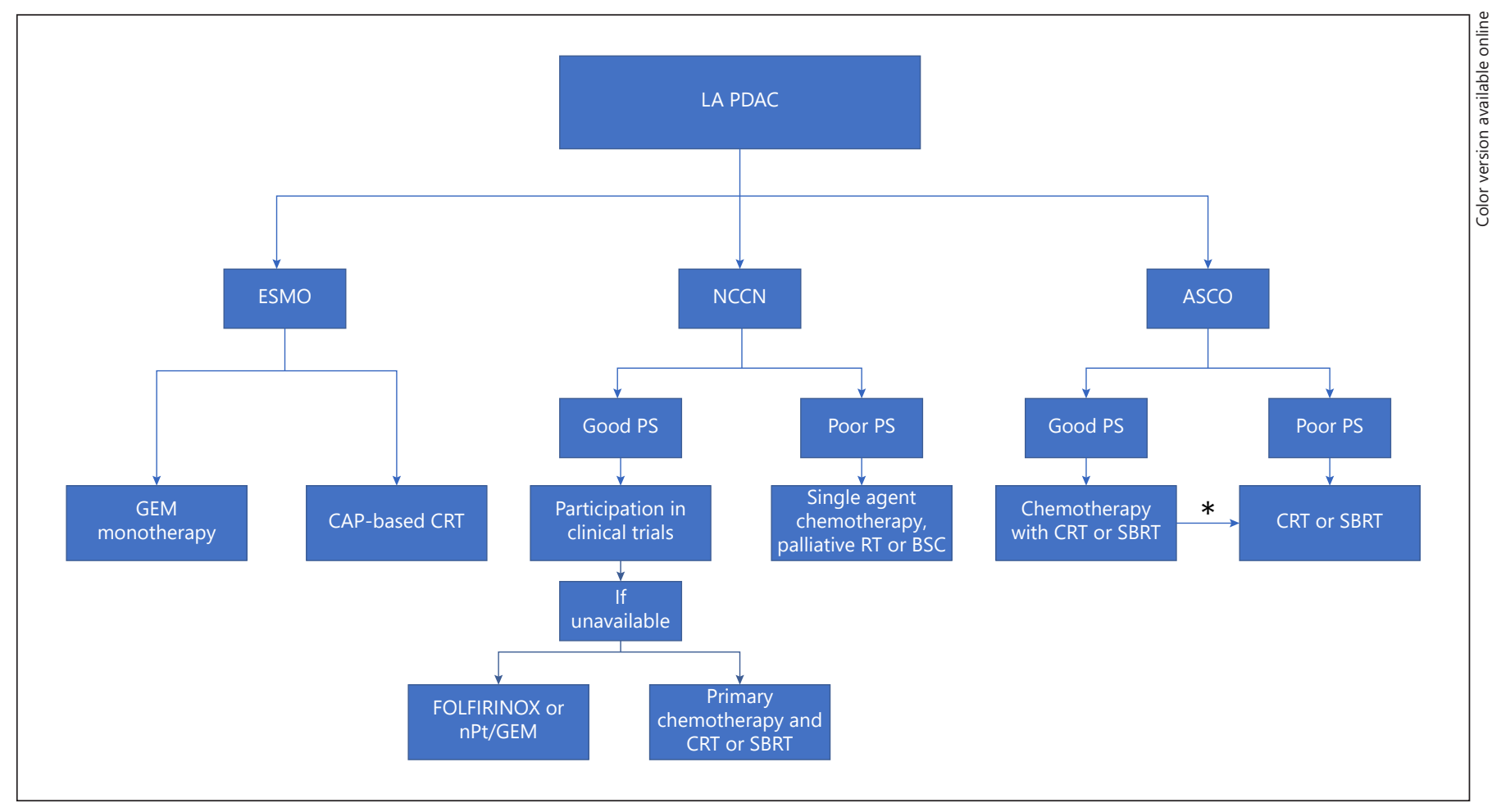

Fig. 1. Therapy guidelines for LA PDAC. *Local disease progression or toxicity. LA PDAC, locally advanced pancreatic ductal adenocarcinoma; ESMO, European Society for Medical Oncology; NCCN, National Comprehensive Cancer Network; ASCO, American Society of Clinical Oncology; PS, performance status; GEM, gemcitabine; CAP, capecitabine; CRT, chemoradiotherapy; RT, radiotherapy; BSC, best supportive care; SBRT, stereotactic body radiation therapy; $\mathrm{nPt}$, nab-paclitaxel.

leading and is not predictive of resectability or pathologic response [49-51]. Instead, the evaluation should also take into account CA 19-9 levels [52], performance status [53, 54], and weight change [55]. Until more accurate assessment of tumor response is available, surgical exploration should be offered to all patients who do not show signs of disease progression under NAT $[56,57]$. Novel biomarkers or biochemical parameters [58] may allow more accurate assessment of the biological tumor response in the future. Several large studies from highvolume centers have reported promising results for patients undergoing NAT for LA PDAC: The Heidelberg group analyzed 575 patients undergoing NAT for LA PDAC (76\%) and metastatic PDAC (24\%). NAT consisted of chemotherapy with FOLFIRINOX $(n=125)$, chemotherapy with gemcitabine + RT $(n=322)$, or various other regimens $(n=128)$. The resection rates were $61 \%$ after FOLFIRINOX, $46 \%$ after gemcitabine and RT, and $52 \%$ after the various other treatments $(p=0.026)$. OS was significantly longer following resection than after exploration alone (15.3 vs. 8.5 months; $p<0.001$ ). Look- ing at the different regimens, OS was 16 months after FOLFIRINOX, 16.5 months after gemcitabine, and 14.5 months after the various other treatments $(p=0.085)$. In the multivariable analysis, FOLFIRINOX was independently associated with a favorable prognosis [44]. The group from Johns Hopkins reported the outcomes of 415 patients with LA PDAC who were treated with FOLFIRINOX-based NAT (50\%), gemcitabine-based NAT (31\%), or a combination of the two (19\%). Of the 116 patients (28\%) undergoing surgical exploration, 84 (20\%) underwent resection of the primary tumor, and in $89 \%$ of these cases, an R0 resection was achieved. OS from the time of diagnosis was 35.3 months for the resection group and 16.2 months for the nonresection group $(p<0.001)$. In the nonresection group, type of NAT was not associated with OS [43]. The group at a third high-volume center, in Boston, reported outcomes on 141 surgically explored patients with LA PDAC (51\%) and BR PDAC (49\%) who underwent NAT with FOLFIRINOX. Resection was achieved in 110 patients (78\%), with an R0 rate of $81 \%$. From the time of diagnosis, the patients with resection 
Table 2. Randomized controlled trials comparing neoadjuvant chemotherapy with upfront surgery for resectable and borderline resectable pancreatic cancer

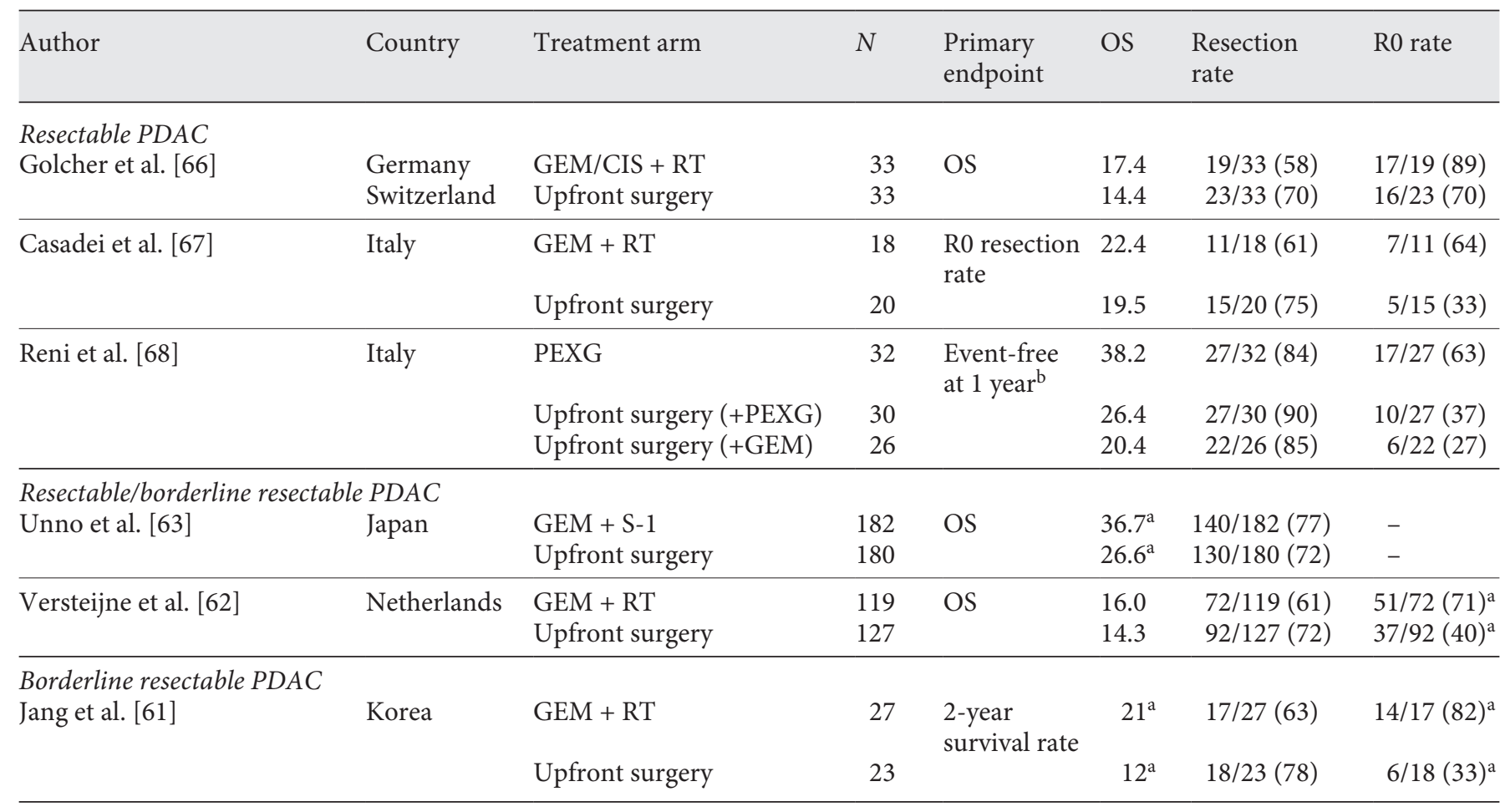

Data are given as $n$ (\%). CIS, cisplatin; GEM, gemcitabine; OS, median overall survival in months by intention-to-treat analysis; PDAC, pancreatic ductal adenocarcinoma; RT, radiotherapy; S-1, oral fluoropyrimidine derivative; PEXG, cisplatin, epirubicin, capecitabine, and gemcitabine. ${ }^{\mathrm{a}} p<0.05$. ${ }^{\mathrm{b}}$ Events defined as progression, relapse, new tumor, distant metastases, or death.

had an OS of 37.7 months, compared to 18.6 months for those without resection [56]. Recently, in a first prospective RCT, the German Pancreatic Cancer Group compared the efficacy and safety of 2 different NAT regimens (FOLFIRINOX vs. nab-paclitaxel/gemcitabine) in LA PDAC. The results were presented at the 2019 ESMO Congress and have been published only as an abstract. The primary endpoint, the rate of conversion to surgery, was $30.6 \%$ with nab-paclitaxel/gemcitabine-based NAT and $45.0 \%$ with FOLFIRINOX-based NAT $(p=0.135)$, while an $\mathrm{R} 0$ resection was achieved in $68 \%$ of cases with nab-paclitaxel/gemcitabine and in $74 \%$ with FOLFIRINOX. This RCT highlights the value of conversion to surgery, as patients whose tumor was resected had significantly longer survival of 27.4 versus 14.2 months ( $p=$ $0.003)$ [59]. Since the studies published to date are heterogenous regarding inclusion and resectability criteria, prospective high-quality studies are needed to evaluate optimal patient selection and the true value of NAT in LA PDAC.

\section{Neoadjuvant Therapy in BR PDAC}

BR PDAC is characterized by venous or limited arterial involvement of the cancer (Table 1) and resectability at the time of diagnosis. Therefore, the main purpose of NAT is to select candidates with favorable tumor biology and not essentially to decrease the tumor size. Although the evidence is limited, the 2019 NCCN guidelines recommend NAT for BR PDAC. Several studies have shown promising outcomes in patients undergoing NAT for BR PDAC, reflecting the value of NAT in patient selection and controlling for potential metastases. In a single-arm phase II clinical trial, Murphy et al. [60] analyzed 48 patients with BR PDAC who were treated by means of neoadjuvant FOLFIRINOX and CRT. Thirty-four patients (79\%) completed all cycles of FOLFIRINOX, and restaging was performed. Seventeen patients had vascular involvement and received long-course CRT with 5-FU and capecitabine. Twenty-seven patients with no vascular involvement received short-course CRT with capecitabine. 
The trial showed favorable results: 32 patients were treated with resection, and in 31 of them, $\mathrm{R} 0$ resection was achieved. While the PFS and 2-year OS were 14.7 months and $56 \%$ for the patients as a whole, those undergoing resection had a PFS of 48.6 months and a 2 -year OS of $72 \%$ [60]. A Korean phase II/III RCT by Jang et al. [61] compared neoadjuvant chemoradiation $\left(400 \mathrm{mg} / \mathrm{m}^{2}\right.$ gemcitabine, 54 Gy radiation) to upfront surgery in patients with BR PDAC (Table 2). Patients with upfront surgery received the same CRT within 8 weeks after resection as the patients with NAT. Following completion of surgery or chemoradiation after 4-6 weeks, adjuvant chemotherapy with gemcitabine was administered in both groups. The study was terminated early after enrolling 58 of the planned 110 patients. In the intention-to-treat analysis, the 2-year survival rate and median survival $(40.7 \%$ and 21 months vs. $26.1 \%$ and 12 months) (hazard ratio 1.495 , $95 \%$ CI $[0.66,3.36] ; p=0.028)$ were significantly better for patients with NAT. However, the study has several limitations: per-protocol analysis included only 8 patients with NAT and 6 patients with upfront surgery and did not show a difference in survival; furthermore, clinical T4 tumors and N1 status were more frequent in the upfront surgery group [61]. These issues limit the validity of the study's conclusions. The recently published multicenter PREOPANC trial is a randomized phase III study including resectable and BR PDAC. Neoadjuvant treatment contained 3 cycles of gemcitabine, combined with radiation $(15 \times 2.4 \mathrm{~Gy})$, followed by surgery and adjuvant chemotherapy with 4 cycles of gemcitabine. Patients assigned to upfront surgery received 6 cycles of adjuvant gemcitabine. A total of 246 patients were analyzed, 133 with resectable PDAC and 113 with BR PDAC. By intention-to-treat analysis, the primary outcome of OS showed no significant difference between the groups ( 16.0 vs. 14.3 months; $p=0.96$ ). The $\mathrm{R} 0$ resection rate was statistically insignificantly higher in patients with NAT (71 vs. $40 \% ; p>0.001$ ). Furthermore, patients with NAT were less likely to have pathologic lymph nodes (33 vs. $78 \%$; $p<0.001)$. The subgroup of patients with BR PDAC showed a significant advantage of NAT (OS: 17.6 vs. 13.2 months; $p=0.029$, DFS: 6.3 vs. 6.2 months; $p=0.013$ ). However, the results of this study should be interpreted with care, as patient selection was poor with a high dropout rate, especially in the upfront surgery group. Furthermore, preoperative suspicious lymph nodes were more often present ( 35 vs. $23 \%$ ), and the baseline CA 19-9 level was higher (257 [83-727] vs. 111 [26-603]) in the upfront surgery group [62]. The Prep-02/JSAP-05-trial from Japan randomized 182 patients with resectable or
BR PDAC to 2 cycles of NAT with gemcitabine and S-1 (an oral fluoropyrimidine derivative) and 180 patients to upfront surgery. The patients in both groups received 6 months of adjuvant chemotherapy. Patients with NAT had a superior OS ( 36.7 vs. 26.6 months; $p=0.015$ ), while there were no differences in resection rates, $\mathrm{R} 0$ resections, or morbidity [63]. Again, the results should be interpreted with care, as S-1 has shown good results in the Asian population, but its performance in Caucasians remains unclear due to the different expression of cytochrome P-450.

The recently published abstract of the ESPAC-5F trial (ISRCTN89500674) provides further evidence in favor of NAT for BR PDAC. Ninety patients were randomized into 4 groups (88 analyzed): (1) upfront surgery, (2) 2 cycles of NAT with gemcitabine + capecitabine, (3) 4 cycles of NAT with FOLFIRINOX, and (4) NAT with capecitabine-based CRT (50.4 Gy). After resection, all patients received NAT (gemcitabine or 5-FU). The resection rate was $62 \%$ for upfront surgery and $55 \%$ for NAT ( $p=0.668$ ), while the rate of $\mathrm{R} 0$ resection was $15 \%$ for upfront surgery and $23 \%$ for NAT $(p=0.721)$. Although the resection rates did not differ significantly, the 1-year survival rate was higher for NAT than for upfront surgery (77 vs. $40 \%$; $p<0.001$ ) [64]. Even though this study was primarily designed to assess recruitment and feasibility for NAT and was not powered for survival, these results may further strengthen the NCCN recommendation that patients with BR PDAC should receive NAT.

\section{Neoadjuvant Therapy in Primary Resectable PDAC}

After the promising results of NAT in BR PDAC and LA PDAC, there is increasing interest in the use of NAT for resectable PDAC (Table 2). As mentioned above, NAT in resectable PDAC could increase the proportion of patients receiving chemotherapy, as half do not receive adjuvant chemotherapy due to postoperative morbidity or poor general condition. Furthermore, chemotherapy delivery is more effective with an intact blood supply to tumor cells than in circumstances of impaired postoperative tissue vascularization [65]. In the first randomized phase II trial on this topic, Golcher et al. [66] planned to evaluate the difference between upfront surgery and NAT with gemcitabine/cisplatin-based CRT followed by surgery in 254 patients. Despite recruitment of patients from 8 institutions in Germany and Switzerland, the study was terminated early because only 73 patients had been recruited in 6 years. The R0 resection rate (upfront surgery: $48 \%$ vs. 
Table 3. Ongoing randomized trials

\begin{tabular}{|c|c|c|c|c|c|}
\hline NCT number & Name & $\begin{array}{l}\text { Sample } \\
\text { size }\end{array}$ & Treatment arm & Primary endpoint & Phase \\
\hline \multicolumn{6}{|l|}{ Resectable PDAC } \\
\hline NCT02562716 & SWOG S1505 & 112 & $\begin{array}{l}\text { mFOLFIRINOX } \\
\text { nPt/GEM }\end{array}$ & 2-year OS & II \\
\hline NCT02919787 & NorPACT-1 & 90 & $\begin{array}{l}\text { FOLFIRINOX } \\
\text { Upfront surgery }\end{array}$ & 1-year OS & $\mathrm{II} / \mathrm{III}$ \\
\hline \multirow[t]{3}{*}{ NCT02959879 } & \multirow[t]{3}{*}{$\begin{array}{l}\text { PANACHE01- } \\
\text { PRODIGE48 }\end{array}$} & \multirow[t]{3}{*}{160} & OLFIRINOX & \multirow[t]{3}{*}{$\begin{array}{l}\text { 1-year survival } \\
\text { Therapy completion }\end{array}$} & \multirow[t]{3}{*}{ II } \\
\hline & & & FOLFOX & & \\
\hline & & & Upfront surgery & & \\
\hline NCT04340141 & ALLIANCE & 352 & $\begin{array}{l}\text { mFOLFIRINOX } \\
\text { Upfront surgery }\end{array}$ & OS & III \\
\hline NCT00727441 & J0810 & $87^{\mathrm{a}}$ & $\begin{array}{l}\text { GVAX } \\
\text { GVAX, cyclophosphamid i.v. } \\
\text { GVAX, cyclophosphamid p.o }\end{array}$ & Safety, immune response & II \\
\hline NCT02047513 & NEONAX & $127^{\mathrm{a}}$ & $\begin{array}{l}\text { nPt/GEM } \\
\text { Upfront surgery }\end{array}$ & DFS & II \\
\hline NCT03750669 & CISPD-1 & 416 & $\begin{array}{l}\text { nPt/GEM and mFOLFIRINOX } \\
\text { Upfront surgery }\end{array}$ & DFS & II \\
\hline NCT01314027 & NEOPAC & $38^{\mathrm{a}}$ & $\begin{array}{l}\text { GEM/oxaliplatin } \\
\text { Upfront surgery }\end{array}$ & Progression-free survival & III \\
\hline NCT03727880 & $\mathrm{J} 18140$ & 36 & $\begin{array}{l}\text { Standard of care NAT + pembrolizumab i.v. } \\
\text { and defactinib } \\
\text { Standard of care NAT + pembrolizumab i.v. }\end{array}$ & $\begin{array}{l}\text { Pathologic complete } \\
\text { response rate }\end{array}$ & II \\
\hline \multirow[t]{2}{*}{ NCT03979066 } & \multirow[t]{2}{*}{ NEOiPANC } & \multirow[t]{2}{*}{40} & Atezolizumab i.v. and PEGPH20 & $\begin{array}{l}\text { Change in CD } 8+\mathrm{T} \text { cells } \\
\text { within tumor }\end{array}$ & II \\
\hline & & & Atezolizumab i.v. & & \\
\hline NCT02451982 & J1568 & 62 & $\begin{array}{l}\text { Low-dose cyclophosphamide, GVAX, } \\
\text { nivolumab } \\
\text { Low-dose cyclophosphamide, GGVAX, } \\
\text { nivolumab, urelumab i.v. } \\
\text { Low-dose cyclophosphamide, GVAX }\end{array}$ & Median IL-17A expression ${ }^{b}$ & $\mathrm{I} / \mathrm{II}$ \\
\hline Resectable/borderlin & sectable PDAC & & & & \\
\hline NCT02172976 & NEPAFOX & $40^{\mathrm{a}}$ & $\begin{array}{l}\text { FOLFIRINOX } \\
\text { Upfront surgery + GEM }\end{array}$ & 2-year OS & II/III \\
\hline NTR7292 & PREOPANC-2 & 368 & $\begin{array}{l}\text { FOLFIRINOX } \\
\text { GEM-based CRT + AT with GEM }\end{array}$ & OS & III \\
\hline NCT02305186 & UVA-PC-PD101 & 56 & $\begin{array}{l}\text { Pembrolizumab + CAP-based CRT } \\
\text { CAP-based CRT }\end{array}$ & $\begin{array}{l}\text { Toxicity, number of } \\
\text { tumor-infiltrating lymphocytes }\end{array}$ & $\mathrm{I} / \mathrm{II}$ \\
\hline NCT01900327 & NEOPA & $32^{\mathrm{a}}$ & $\begin{array}{l}\text { GEM-based CRT with external beam } \\
\text { radiation } \\
\text { Upfront surgery }\end{array}$ & 3-year survival rate & III \\
\hline NCT01978184 & UPCI\# 13-074 & $104^{\mathrm{a}}$ & $\begin{array}{l}\text { nPt/GEM and hydroxychloroquine } \\
\text { nPt/GEM }\end{array}$ & Histopathologic response & II \\
\hline Borderline resectable & $A C$ & & & & \\
\hline ISRCTN89500674 & ESPAC-5F & $90^{\mathrm{a}}$ & $\begin{array}{l}\text { FOLFIRINOX } \\
\text { GEM and CAP } \\
\text { NAT with CAP-based CRT } \\
\text { Upfront surgery }\end{array}$ & Recruitment, resection rate & II \\
\hline
\end{tabular}


Table 3 (continued)

\begin{tabular}{llclc}
\hline NCT number & Name & $\begin{array}{l}\text { Sample } \\
\text { size }\end{array}$ & Treatment arm & Primary endpoint \\
\hline NCT02676349 & $\begin{array}{l}\text { PANDAS- } \\
\text { PRODIGE } 44\end{array}$ & 90 & mFOLFIRINOX + CAP-based CRT & R0 resection rate \\
\hline NCT02839343 & ALLIANCE & $126^{\mathrm{a}}$ & mFOLFIRINOX & OS rate \\
& A021501 & & mFOLFIRINOX + SBRT & OS \\
\hline NCT03777462 & BRPCNCC-1 & 150 & $\begin{array}{l}\text { nPt/GEM + SBRT } \\
\text { S1/nPt + SBRT } \\
\text { nPt/GEM }\end{array}$ & II \\
\hline NCT02717091 & NUDC1508 & 50 & $\begin{array}{l}\text { FOLFIRINOX } \\
\text { nPt/GEM }\end{array}$ & R0 resection rate
\end{tabular}

OS, overall survival; nPt, nab-paclitaxel; GEM, gemcitabine; GVAX, GM-CSF (granulocyte macrophage colony-stimulating factor) secreting allogeneic pancreatic cancer vaccine; DFS, disease-free survival; NAT, neoadjuvant treatment; CAP, capecitabine; AT, adjuvant treatment; CRT, chemoradiotherapy; SBRT, stereotactic body radiation therapy; NCT, National Clinical Trial. ${ }^{a}$ Actual enrollment. ${ }^{b}$ In vaccine-induced lymphoid aggregates found in surgically resected pancreatic tumors.

NAT: $52 \% ; p=0.81$ ) and OS (upfront surgery: 14.4 months vs. NAT: 17.4 months; $p=0.96$ ) were similar [66]. The RCT conducted by Casadei et al. [67] compared upfront surgery to NAT consisting of 2 cycles of gemcitabine followed by combined gemcitabine-based CRT. To detect a difference in $\mathrm{R} 0$ resection rate of $35 \%$, a sample size of 32 patients per arm was calculated. The study was stopped after 6 years due to low accrual rate (38 patients). Neither the $\mathrm{R} 0$ resection rate (upfront surgery: $25 \%$ vs. NAT: $38.9 \% ; p=0.489$ ) nor OS (upfront surgery: 19.5 vs. NAT: $22.4 ; p=0.973$ ) differed statistically significantly [67].

The Italian PACT-15 study randomized 88 patients into 3 groups: (1) upfront resection followed by adjuvant chemotherapy with gemcitabine, (2) upfront resection followed by adjuvant chemotherapy with PEXG (cisplatin $30 \mathrm{mg} / \mathrm{m}^{2}$, epirubicin $30 \mathrm{mg} / \mathrm{m}^{2}$, gemcitabine $800 \mathrm{mg} / \mathrm{m}^{2}$, and oral capecitabine $1,250 \mathrm{mg} / \mathrm{m}^{2}$ ), and (3) NAT with PEXG, resection followed by adjuvant chemotherapy with PEXG (3 months' preoperative and 3 months' postoperative chemotherapy). The primary endpoint was the proportion of patients who were event-free after 1 year (with events defined as disease progression, local recurrence, distant metastasis, new tumor, or death). Twenty-three percent were event-free with adjuvant gemcitabine, 50\% with adjuvant PEXG, and 66\% with neoadjuvant PEXG. The median survival after NAT was 38.2 months, compared to 20.4 months with adjuvant gemcitabine and 26.2 months with adjuvant PEXG [68]. Of note, the phase III PREOPANC study, including both BR PDAC and resect- able PDAC, showed no benefit in OS for NAT. Furthermore, the subgroup analysis of 133 randomized resectable patients detected no difference in OS, DFS, resection rate, or R0 rate [62]. Several RCTs are currently investigating potential benefits of NAT in resectable PDAC with different chemotherapeutic agents (Table 3). Both the Norwegian NorPACT-1 trial (NCT02919787) and the French Panache-01 trial (NCT02959879) are evaluating the effect of NAT with FOLFIRINOX. In Germany, the NEONAX trial (NCT02047513) has completed recruitment of 166 patients receiving NAT with 2 cycles of nab-paclitaxel/ gemcitabine, while the Swiss-led NEOPAC study (NCT01314027) looking at NAT with gemcitabine/oxaliplatin was terminated due to low recruitment.

\section{Conclusion}

Modern chemotherapy regimens have improved outcomes of PDAC, and experts worldwide agree that a multidisciplinary treatment approach is beneficial. Factors such as better patient selection and improved locoregional and systemic control favor NAT in PDAC. Nevertheless, high-level evidence remains sparse. NAT is routinely applied in LA PDAC, and there is increasing evidence demonstrating benefits of NAT in BR PDAC. However, the most effective NAT regimen (chemotherapy, radiochemotherapy, or a combination thereof) needs to be evaluated in future randomized trials. Based on the avail- 
able evidence, NAT does not offer benefits compared to upfront resection in patients with resectable PDAC and should be used only in clinical trials. Until more accurate predictors of resectability are available, selection of suitable candidates for surgical resection after NAT should not be based on cross-sectional imaging alone but should also take CA 19-9 levels and performance status into account. Surgical exploration should be offered to all patients without signs of disease progression under NAT. Several ongoing RCTs will provide more evidence on patient selection, potential benefits, and whether NAT should be FOLFIRINOX- or gemcitabine-based.

\section{Statement of Ethics}

This review article is not a primary study with participants. No ethical approval is required.

\section{Conflict of Interest Statement} close.

\section{Funding Sources}

The study was funded by institutional means of the Klinik Beau-Site.

\section{Author Contributions}

P.C.M., M.C.F., and U.K. performed literature search, drafted the manuscript, and created tables and figures; C.M.R., F.N., C.J., C.G., T.H., and K.Z. performed literature search and critical revision of the manuscript.

\section{References}

1 Siegel RL, Fedewa SA, Miller KD, GodingSauer A, Pinheiro PS, Martinez-Tyson D, et al. Cancer statistics for Hispanics/Latinos, 2015. CA Cancer J Clin. 2020;65(6):457-80.

2 NICER. National Institute for Cancer Epidemiology and Registration [Internet]. 2015.

3 Alexakis N, Halloran C, Raraty M, Ghaneh P, Sutton R, Neoptolemos JP. Current standards of surgery for pancreatic cancer. Br J Surg. 2004;91(11):1410-27.

4 Li D, Xie K, Wolff R, Abbruzzese JL. Pancreatic cancer. Lancet. 2004;363(9414):1049-57.

5 Van Hagen P, Hulshof MC, van Lanschot JJ, Steyerberg EW, Van Berge Henegouwen MI, Wijnhoven BP, et al. Preoperative chemoradiotherapy for esophageal or junctional cancer. N Engl J Med. 2012;366(22):2074-84.

6 Oppedijk V, Van Der Gaast A, van Lanschot JJ, Van Hagen P, Van Os R, Van Rij CM, et al. Patterns of recurrence after surgery alone versus preoperative chemoradiotherapy and surgery in the CROSS trials. J Clin Oncol. 2014 32(5):385-91.

7 Shapiro J, van Lanschot JJB, Hulshof MCCM, van Hagen P, van Berge Henegouwen MI, Wijnhoven BPL, et al. Neoadjuvant chemoradiotherapy plus surgery versus surgery alone for oesophageal or junctional cancer (CROSS): long-term results of a randomised controlled trial. Lancet Oncol. 2015;16(9):1090-8.

8 Das P, Skibber JM, Rodriguez-Bigas MA, Feig BW, Chang GJ, Wolff RA, et al. Predictors of tumor response and downstaging in patients who receive preoperative chemoradiation for rectal cancer. Cancer. 2007;109(9):1750-5.

9 Collette L, Bosset JF, Den Dulk M, Nguyen F, Mineur L, Maingon P, et al. Patients with curative resection of cT3-4 rectal cancer after preoperative radiotherapy or radiochemotherapy: does anybody benefit from ad- juvant fluorouracil-based chemotherapy? A trial of the European organisation for research and treatment of cancer radiation oncology group. J Clin Oncol. 2007;25(28): 4379-86.

10 Smith KD, Tan D, Das P, Chang GJ, Kattepogu K, Feig BW, et al. Clinical significance of acellular mucin in rectal adenocarcinoma patients with a pathologic complete response to preoperative chemoradiation. Ann Surg. 2010;251(2):261-4.

11 Shivnani AT, Small W, Stryker SJ, Kiel KD, Lim S, Halverson AL, et al. Preoperative chemoradiation for rectal cancer: results of multimodality management and analysis of prognostic factors. Am J Surg. 2007;193(3): 389-4.

12 Cunningham D, Allum WH, Stenning SP Thompson JN, Van De Velde CJ, Nicolson M, et al. Perioperative chemotherapy versus surgery alone for resectable gastroesophageal cancer. N Engl J Med. 2006;355(1):11-20.

13 Al-Batran SE, Hofheinz RD, Pauligk C, Kopp HG, Haag GM, Luley KB, et al. Histopathological regression after neoadjuvant docetaxel, oxaliplatin, fluorouracil, and leucovorin versus epirubicin, cisplatin, and fluorouracil or capecitabine in patients with resectable gastric or gastro-oesophageal junction adenocarcinoma (FLOT4-AIO): results from the phase 2 part of a multicentre, open-label, randomised phase 2/3 trial. Lancet Oncol. 2016; 17(12):1697-708.

14 Al-Batran SE, Homann N, Pauligk C, Goetze TO, Meiler J, Kasper S, et al. Perioperative chemotherapy with fluorouracil plus leucovorin, oxaliplatin, and docetaxel versus fluorouracil or capecitabine plus cisplatin and epirubicin for locally advanced, resectable gastric or gastro-oesophageal junction adenocarcinoma (FLOT4): a randomised, phase 2/3 trial. Lancet. 2019;393(10184): 1948-57.

15 Gillen S, Schuster T, Meyer Zum Büschenfelde C, Friess H, Kleeff J. Preoperative/neoadjuvant therapy in pancreatic cancer: a systematic review and meta-analysis of response and resection percentages. PLoS Med. 2010;7(4): e1000267.

16 Katz MHG, Shi Q, Ahmad SA, Herman JM, Marsh RDW, Collisson E, et al. Preoperative modified FOLFIRINOX treatment followed by capecitabine-based chemoradiation for borderline resectable pancreatic cancer alliance for clinical trials in oncology trial A021101. JAMA Surg. 2016;151(8):e161137.

17 Mellon EA, Hoffe SE, Springett GM, Frakes JM, Strom TJ, Hodul PJ, et al. Long-term outcomes of induction chemotherapy and neoadjuvant stereotactic body radiotherapy for borderline resectable and locally advanced pancreatic adenocarcinoma. Acta Oncol. 2015;54(7):979-85.

18 Boone BA, Steve J, Krasinskas AM, Zureikat AH, Lembersky BC, Gibson MK, et al. Outcomes with FOLFIRINOX for borderline resectable and locally unresectable pancreatic cancer. J Surg Oncol. 2013;108(4):236-41.

$19 \mathrm{Wu}$ W, He J, Cameron JL, Makary M, Soares $\mathrm{K}$, Ahuja N, et al. The impact of postoperative complications on the administration of adjuvant therapy following pancreaticoduodenectomy for adenocarcinoma. Ann Surg Oncol. 2014;21(9):2873-81.

20 Mayo SC, Gilson MM, Herman JM, Cameron JL, Nathan H, Edil BH, et al. Management of patients with pancreatic adenocarcinoma: national trends in patient selection, operative management, and use of adjuvant therapy. J Am Coll Surg. 2012;214(1):33-45. 
21 Merkow RP, Bilimoria KY, Tomlinson JS, Paruch JL, Fleming JB, Talamonti MS, et al. Postoperative complications reduce adjuvant chemotherapy use in resectable pancreatic cancer. Ann Surg. 2014;260(2):3727.

22 Murphy JE, Ly L, Wo JY-L, Ryan DP, Clark JW, Yeap BY, et al. Dose intensity of neoadjuvant FOLFIRINOX (FFX) in borderline and locally advanced pancreatic cancer (LAPC): a comparison to the adjuvant benchmark. J Clin Oncol. 2019;37(4_Suppl 1):392.

23 Heinrich S, Pestalozzi BC, Schäfer M, Weber A, Bauerfeind P, Knuth A, et al. Prospective phase II trial of neoadjuvant chemotherapy with gemcitabine and cisplatin for resectable adenocarcinoma of the pancreatic head. J Clin Oncol. 2008;26(15):2526-31.

24 Heinrich S, Besselink M, Moehler M, Van Laethem JL, Ducreux M, Grimminger P, et al. Opinions and use of neoadjuvant therapy for resectable, borderline resectable, and locally advanced pancreatic cancer: international survey and case-vignette study. BMC Cancer. 2019;19(1):675

25 Strobel O, Hank T, Hinz U, Bergmann F, Schneider L, Springfeld C, et al. Pancreatic cancer surgery: the new R-status counts. Ann Surg. 2016;265(3):565-73.

26 van Roessel S, Kasumova GG, Tabatabaie O, Ng SC, van Rijssen LB, Verheij J, et al. Pathological margin clearance and survival after pancreaticoduodenectomy in a US and European pancreatic center. Ann Surg Oncol. 2018;25(6):1760-7.

27 Verbeke CS, Leitch D, Menon KV, McMahon MJ, Guillou PJ, Anthoney A. Redefining the R1 resection in pancreatic cancer. Br J Surg. 2006;93(10):1232-7.

28 Ferrone CR, Finkelstein DM, Thayer SP, Muzikansky A, Fernandez-delCastillo C, Warshaw AL. Perioperative CA19-9 levels can predict stage and survival in patients with resectable pancreatic adenocarcinoma. J Clin Oncol. 2006;24(18):2897-902.

29 Hartwig W, Strobel O, Hinz U, Fritz S, Hackert T, Roth C, et al. CA19-9 in potentially resectable pancreatic cancer: perspective to adjust surgical and perioperative therapy. Ann Surg Oncol. 2013;20(7):2188-96.

30 Isaji S, Mizuno S, Windsor JA, Bassi C, Fernández-Del Castillo C, Hackert T, et al. International consensus on definition and criteria of borderline resectable pancreatic ductal adenocarcinoma 2017. Pancreatology. 2018; 18(1):2-11

31 Stonko DP, He J, Zheng L, Blair AB. A contemporary evidence basis for neoadjuvant chemotherapy in upfront resectable pancreatic adenocarcinoma. J Pancreatology. 2020; $3(1): 12-20$

32 Tsen A, Barbara M, Rosenkranz L. Dilemma of elevated CA 19-9 in biliary pathology. Pancreatology. 2018;18(8):862-7.

33 Mann DV, Edwards R, Ho S, Lau WY, Glazer G. Elevated tumour marker CA19-9: clinical interpretation and influence of obstructive jaundice. Eur J Surg Oncol. 2000; 26(5):474-9.

34 Tzeng CW, Fleming JB, Lee JE, Xiao L, Pisters PW, Vauthey JN, et al. Defined clinical classifications are associated with outcome of patients with anatomically resectable pancreatic adenocarcinoma treated with neoadjuvant therapy. Ann Surg Oncol. 2012;19(6):204553.

35 Neoptolemos JP, Stocken DD, Friess H, Bassi C, Dunn JA, Hickey H, et al. A randomized trial of chemoradiotherapy and chemotherapy after resection of pancreatic cancer. $N$ Engl J Med. 2004;350(12):1200-10.

36 Oettle H, Neuhaus P, Hochhaus A, Hartmann JT, Gellert K, Ridwelski K, et al. Adjuvant chemotherapy with gemcitabine and long-term outcomes among patients with resected pancreatic cancer: the CONKO-001 randomized trial. JAMA. 2013;310(14):1473-81.

37 Neoptolemos JP, Stocken DD, Bassi C, Ghaneh P, Cunningham D, Goldstein D, et al. Adjuvant chemotherapy with fluorouracil plus folinic acid vs gemcitabine following pancreatic cancer resection: a randomized controlled trial. JAMA. 2010;304(10):107381.

38 Neoptolemos JP, Palmer DH, Ghaneh P, Psarelli EE, Valle JW, Halloran CM, et al. Comparison of adjuvant gemcitabine and capecitabine with gemcitabine monotherapy in patients with resected pancreatic cancer (ESPAC-4): a multicentre, open-label, randomised, phase 3 trial. Lancet. 2017; 389(10073):1011-24.

39 Conroy T, Hammel P, Hebbar M, Ben Abdelghani M, Wei AC, Raoul JL, et al. FOLFIRINOX or gemcitabine as adjuvant therapy for pancreatic cancer. N Engl J Med. 2018; 379(25):2395-406.

40 Tempero MA, Cardin DB, Biankin A, Goldstein D, Moore M, O'Reilly EM, et al. APACT: a phase 3 randomized, open-label, multicenter trial evaluating the use of adjuvant nab-paclitaxel (nab-P) plus gemcitabine $(G)$ versus $\mathrm{G}$ alone in patients (pts) with surgically resected ductal pancreatic adenocarcinoma (PDA). J Clin Oncol. 2014;32(15_Suppl 1): TPS4162.

41 Seufferlein T, Hammel P, Delpero JR, Macarulla T, Pfeiffer P, Prager GW, et al. Optimizing the management of locally advanced pancreatic cancer with a focus on induction chemotherapy: expert opinion based on a review of current evidence. Cancer Treat Rev. 2019; 77:1-10.

42 Furuse J, Shibahara J, Sugiyama M. Development of chemotherapy and significance of conversion surgery after chemotherapy in unresectable pancreatic cancer. J Hepatobiliary Pancreat Sci. 2018;25(5):261-8.

43 Gemenetzis G, Groot VP, Blair AB, Laheru DA, Zheng L, Narang AK, et al. Survival in locally advanced pancreatic cancer after neoadjuvant therapy and surgical resection. Ann Surg. 2019;270(2):340-7.
44 Hackert T, Sachsenmaier M, Hinz U, Schneider L, Michalski CW, Springfeld C, et al. Locally advanced pancreatic cancer: neoadjuvant therapy with folfirinox results in resectability in $60 \%$ of the patients. Ann Surg. 2016; 264(3):457-63.

45 Rombouts SJ, Walma MS, Vogel JA, van Rijssen LB, Wilmink JW, Mohammad NH, et al. Systematic review of resection rates and clinical outcomes after FOLFIRINOX-based treatment in patients with locally advanced pancreatic cancer. Ann Surg Oncol. 2016; 23(13):4352-60.

46 Ducreux M, Cuhna AS, Caramella C, Hollebecque A, Burtin P, Goéré D, et al. Cancer of the pancreas: ESMO clinical practice guidelines for diagnosis, treatment and follow-up. Ann Oncol. 2015;26(Suppl 5):v56-68.

47 Tempero MA, Malafa MP, Chiorean EG, Czito B, Scaife C, Narang AK, et al. Pancreatic adenocarcinoma, version 1.2019 featured updates to the NCCN guidelines. JNCCN J Natl Compr Cancer Netw. 2019;17(3):203-10.

48 Balaban EP, Mangu PB, Khorana AA, Shah MA, Mukherjee S, Crane $\mathrm{CH}$, et al. Locally advanced, unresectable pancreatic cancer: American society of clinical oncology clinical practice guideline. J Clin Oncol. 2016;34(22): 2654-68.

49 Ferrone CR, Marchegiani G, Hong TS, Ryan DP, Deshpande V, McDonnell EI, et al. Radiological and surgical implications of neoadjuvant treatment with FOLFIRINOX for locally advanced and borderline resectable pancreatic cancer. Ann Surg. 2015;261(1): 12-7.

50 Godhi SA, Parasar K, Saluja S, Mishra P. Radiological and surgical implications of neoadjuvant treatment with FOLFIRINOX for locally advanced and borderline resectable pancreatic cancer. Ann Surg. 2017;265(6):e73.

51 Wagner M, Antunes C, Pietrasz D, Cassinotto C, Zappa M, Sa Cunha A, et al. CT evaluation after neoadjuvant FOLFIRINOX chemotherapy for borderline and locally advanced pancreatic adenocarcinoma. Eur Radiol. 2017; 27(7):3104-16.

52 Chang JC, Kundranda M. Novel diagnostic and predictive biomarkers in pancreatic adenocarcinoma. Int J Mol Sci. 2017;18(3):667.

53 Vernerey D, Huguet F, Vienot A, Goldstein D, Paget-Bailly S, Van Laethem JL, et al. Prognostic nomogram and score to predict overall survival in locally advanced untreated pancreatic cancer (PROLAP). Br J Cancer. 2016; 115(3):281-9.

54 Khorana AA, Mangu PB, Berlin J, Engebretson A, Hong TS, Maitra A, et al. Potentially curable pancreatic cancer: American society of clinical oncology clinical practice guideline update. J Clin Oncol. 2016;35(20):2324-8.

55 Naumann P, Habermehl D, Welzel T, Debus J, Combs SE. Outcome after neoadjuvant chemoradiation and correlation with nutritional status in patients with locally advanced pancreatic cancer. Strahlenther Onkol. 2013; 189(9):745-52. 
56 Michelakos T, Pergolini I, Castillo CF, Honselmann KC, Cai L, Deshpande V, et al. Predictors of resectability and survival in patients with borderline and locally advanced pancreatic cancer who underwent neoadjuvant treatment with FOLFIRINOX. Ann Surg. 2019;269(4):733-40.

57 Rangelova E, Wefer A, Persson S, Valente R, Tanaka K, Orsini N, et al. Surgery improves survival after neoadjuvant therapy for borderline and locally advanced pancreatic cancer: a single institution experience. Ann Surg. 2019;1.

58 Alagappan M, Pollom EL, Von Eyben R, Kozak MM, Aggarwal S, Poultsides GA, et al. Albumin and neutrophil-lymphocyte ratio (NLR) predict survival in patients with pancreatic adenocarcinoma treated with SBRT. Am J Clin Oncol. 2018;41(3):242-7.

59 Kunzmann V, Algül H, Goekkurt E, Siegler GM, Martens UM, Waldschmidt D, et al. Conversion rate in locally advanced pancreatic cancer (LAPC) after nab-paclitaxel/gemcitabine- or FOLFIRINOX-based induction chemotherapy (NEOLAP): final results of a multicenter randomised phase II AIO trial. Ann Oncol. 2019;30:v253.

60 Murphy JE, Wo JY, Ryan DP, Jiang W, Yeap BY, Drapek LC, et al. Total neoadjuvant therapy with FOLFIRINOX followed by individualized chemoradiotherapy for borderline resectable pancreatic adenocarcinoma: a phase 2 clinical trial. JAMA Oncol. 2018;4(7):963-9.
61 Jang JY, Han Y, Lee H, Kim SW, Kwon W, Lee $\mathrm{KH}$, et al. Oncological benefits of neoadjuvant chemoradiation with gemcitabine versus upfront surgery in patients with borderline resectable pancreatic cancer: a prospective, randomized, open-label, multicenter phase $2 / 3$ trial. Ann Surg. 2018;268(2):215-22.

62 Versteijne E, Suker M, Groothuis K, Akkermans-Vogelaar JM, Besselink MG, Bonsing BA, et al. Preoperative chemoradiotherapy versus immediate surgery for resectable and borderline resectable pancreatic cancer: results of the Dutch randomized phase III PREOPANC trial. J Clin Oncol. 2020 Jun 1;38(16): 1763-73.

63 Unno M, Motoi F, Matsuyama Y, Satoi S, Matsumoto I, Aosasa S, et al. Randomized phase II/III trial of neoadjuvant chemotherapy with gemcitabine and S-1 versus upfront surgery for resectable pancreatic cancer (Prep-02/JSAP-05). J Clin Oncol. 2019 Feb 1; 49(2):190-4.

64 Ghaneh P, Palmer DH, Cicconi S, Halloran C, Psarelli EE, Rawcliffe CL, et al. ESPAC-5F: four-arm, prospective, multicenter, international randomized phase II trial of immediate surgery compared with neoadjuvant gemcitabine plus capecitabine (GEMCAP) or FOLFIRINOX or chemoradiotherapy (CRT) in patients with borderline resectable pancreatic cancer. J Clin Oncol.2020;38(15_Suppl 1): 4505 .
65 Crane CH, Varadhachary G, Wolff RA, Pisters PW, Evans DB. The argument for preoperative chemoradiation for localized, radiographically resectable pancreatic cancer. Best Pract Res Clin Gastroenterol. 2006;20(2): 365-82.

66 Golcher H, Brunner TB, Witzigmann H, Marti L, Bechstein W-O, Bruns C, et al. Neoadjuvant chemoradiation therapy with gemcitabine/cisplatin and surgery versus immediate surgery in resectable pancreatic cancer. Strahlenther Onkol. 2014;191(1):7-16.

67 Casadei R, Di Marco M, Ricci C, Santini D, Serra C, Calculli L, et al. Neoadjuvant chemoradiotherapy and surgery versus surgery alone in resectable pancreatic cancer: a singlecenter prospective, randomized, controlled trial which failed to achieve accrual targets. J Gastrointest Surg. 2015;19(10):1802-12.

68 Reni M, Balzano G, Zanon S, Zerbi A, Rimassa L, Castoldi R, et al. Safety and efficacy of preoperative or postoperative chemotherapy for resectable pancreatic adenocarcinoma (PACT-15): a randomised, open-label, phase 2-3 trial. Lancet Gastroenterol Hepatol. 2018; $3(6): 413-23$. 